\title{
Att forska om utsatta
}

\author{
HANS SW $\ddot{A} R D$
}

Hur skall vi forska om människor som befinner sigi en utsatt situation? Hur skall vi kunna upptäcka och tränga igenom myter och föreställningar som ofta omger marginaliserade grupper? Har vi rätt att ställa närgångna frågor om alkohol-och drogmissbruk? Kan vi forskare förstå människor som lever ett liv som är annorlunda än det liv som majoriteten av medborgarna lever?

Jag har under flera år forskat om hemlösa och hemlöshet. Många hemlösa är utsatta under perioder och jag skall använda dem som illustration för att diskutera de inledande frågorna.

Det är viktigt att diskutera metodologiska och forskningsetiska problem i forskningen runt hemlösa och andra utsatta grupper i samhället. Inom den amerikanska hemlöshetsforskningen förs en mer livlig diskussion om sådana här frågor. Det kan ha att göra med att denna forskning är mer utvecklad i USA och att man har starkare intresseorganisationer som för de hemlösas talan och medvetet försöker att tvätta bort de negativa beskrivningar som ständigt görs

Hans Swärd är docent i socialt arbete och innehar en forskarassistenttjänst finanserad av Socialvetenskapliga forskningsrådet. av den här gruppen. I Sverige finns inte samma tryck från klientorganisationerna.

Två frågor skall diskuteras. Den första handlar om forskningsetiska och moraliska problem. Vilka perspektiv skall vi välja och vilka konsekvenser får valet av olika perspektiv, t.ex. om vi utgår ifrån att det är samhället eller den enskilde som bär skulden till problemen? Vilka etiska dilemmor finns i forskningen? Den andra frågan handlar om metodologiska frågor och har att göra med hur vi skall forska om, tolka och förstå utsatta grupper.

\section{Att beteckna och beskriva utsatta}

Redan att hitta begrepp eller ord för utsatta grupper skapar problem och olika benämningar används av myndigheterna, pressen 
och forskarna. Benämningarna kan leda vårt tänkande i en viss riktning och ha betydelse för perspektivval.

Fattigdomshistoriker och forskare som beskrivit de sociala problemens historia (Himmelfarb 1984, Petersson 1983, Foucault 1986, 1987) har visat hur "den degenererade gruppen", "mobben" eller de "förfallnau utpekats som farliga och tillskrivits djuriska manér och beteenden som lättja och fallenhet för starka drycker, våldsamhet, råhet och förfall. Det finns gamla tankefigurer som ständigt återkommer genom historien och är lätta att ta till i beskrivningar av personer som inte lever upp till majoritetssamhällets krav på "normalitet».

Myndigheterna använder i dag ibland begreppet "tunga fall" på en grupp personer som saknar arbete, bostad, familj och som lever på bidrag eller pension (Järvinen 1998). Det talas också om "tunga klienter«. Socialtjänstens klienter förknippas ofta med personer som har sociala problem orsakade av individuella brister (Abo El Nasr 1989, Salonen 1998). Ofta avgränsas den här gruppen negativt och det finns uppfattningar om att individerna är omotiverade och har missbruks- eller psykiska problem.

Margaretha Järvinen (1998), som under många år har forskat om utsatta människor, använder i sin senaste bok benämningen Det dårlige selskap på en grupp socialt utsatta missbrukare som inte passar in i behandlingssystemen. Begreppet har hon hämtat från en dikt som beskriver barn som ingen vill leka med, de som är ett dåligt sällskap, har dålig karaktär och billig fantasi. Det är en grupp som är utdefinierade och lågt prioriterade av myndigheterna. Sven Hessle (1977), som mycket tidigt började diskutera etiska och moraliska frågor i forskningen om de allra fattigaste, använder begreppet $u t$ satta. Andra begrepp som förekommit är de som lever på samhällets botten ${ }^{1}$, marginaliserade, socialt utslagna, ${ }^{2}$ blommor frän rännstenen, ${ }^{3}$ fyllegubbar, fylleprolitariatet, ${ }^{5}$ svaga grupper. ${ }^{6}$ När makarna Inghe på 1970-talet beskrev hemlösa och utslagna talade de om bottenskrapet bland de misslyckade och utstötta och »det misslyckade 'spillet' från samhällets vårdorgan" (Inghe \& Inghe 1970, s. 248, 267).

En del av de här begreppen kan leda tankarna fel. En hel grupp får bära egenskaper som gäller några få. Alla klienter eller hemlösa har inte svåra anpassningsproblem som ofta våra föreställningar anger (Salonen 1998).

Järvinen (1998) menar att "tunga missbrukare» är ett begrepp som upplöser sig självt ju närmare man kommer dem som stämplas som tunga fall. Det finns föreställningar om att »de tunga fallen« är omotiverade för vård eller att de fått så mycket vård att behandlingen inte skulle bita på dem längre. Problemet är dock, enligt Järvinen, att många "tunga missbrukare» är lågt prioriterade av myndigheterna och inte får någon vård alls. Föreställningarna stämmer inte med verkligheten. När jag har forskat om hemlösa har jag av liknande skäl som Järvinen kommit att bli alltmer tveksam till själva hemlöshetsbegreppet. Många av de

\footnotetext{
1 Grosin \& Norman (1974).

2 Isaksson, Norman \& Svedberg (1978).

3 Espeland (1981).

4 Hagelin (1977).

5 Ramsø, Burmann, Johansen, \& Kalberg (1971).

6 Wiktorin (1980).
} 
hemlösa som jag intervjuat känner inte igen sig i begreppet. Den moderna hemlöshetsforskningen tyder på att hemlöshet mer bör knytas till situationer än till personer (Culhane \& Kuhn 1998, Wagner 1993, Ralston 1996, Swärd 1998). Hemlöshet är inget permanent tillstånd, utan är knutet till vissa perioder i de "hemlösas" liv. Begreppet fattiga skulle förmodligen vara en mycket mer relevant beskrivning på de flesta hemlösa.

Vad jag vill ha sagt är att det är besvärligt att handskas med begrepp som är intecknade av ideologiska föreställningar och det är lätt att ta med de här föreställningarna och bygga in dem i utgångspunkterna för våra undersökningar.

\section{Att studera hemlösa eller att studera hemlöshet}

Den amerikanske forskaren Jim Baumohl (1996) diskuterar vikten av att medvetet välja perspektiv, samt att reflektera över vilka konsekvenser valen får. ${ }^{7}$ Han menar att vi måste göra en distinktion mellan hemlösa och hemlöshet. Undersöker vi hemlösa människor och deras personliga förhållanden under en akut hemlöshetsperiod kommer vi att finna tecken på personlig svaghet.

Då kommer sannolikt sådana förhållanden som missbruk, psykisk särart och uppgifter om att de hemlösa själva valt sin hemlöshet att lyftas fram. Hemlöshet däremot inrymmer, som andra sociala problem, socioekonomiska förhållanden som existerar utanför dem som drabbas av dem. Tittar vi på hem-

7 Liknande frågor behandlar också Rosmari Eliasson i boken Forskningsetik och perspektivval (1995). lösheten som socialt problem är det lättare att vi finner svagheter och luckor i bostadspolitiken, fördelningspolitiken eller i socialpolitiken. Var vi lägger tyngdpunkten - på de hemlösa individerna eller på hemlösheten som socialt problem - kommer att ha konsekvenser för valet av forskningsstrategier och det kommer att ha betydelse för vilka resultat vi kommer att få.

Ingrid Sahlin (1992) som för ett liknande resonemang har visat ett det finns nära samband mellan definitioner och benämningar av hemlösa, föreställningar om orsaker, undersökningars uppläggningar och förslag till åtgärder. Hon menar liksom Baumohl att det finns två konkurrerande huvudperspektiv på hemlösheten som leder till olika metodologiska implikationer. Det ena perspektivet tar sin utgångspunkt i de hemlösas asocialitet och lägger sin tonvikt vid hur de hemlösa skall vårdas och behandlas. Det andra perspektivet är bostadsrelaterat och tar sin utgångspunkt $\mathrm{i}$ bl.a. utvärdering och planering av byggande och fördelande av bostäder.

Många undersökningar både i Sverige och USA har kartlagt den här gruppen ur ett individperspektiv. I majoriteten av de undersökningar och kartläggningar som har gjorts av myndigheter och FOU-enheter i Sverige under 1990-talet har frågor ingått som bl.a. handlar om de hemlösa använder alkohol, teknisk sprit, narkotika, lösningsmedel eller tabletter eller om de lider av psykisk eller fysisk sjukdom (t.ex. Socialstyrelsen 1994:15, Christophs 1997, Ågren 1997). Det finns skäl för myndigheterna göra sådana här undersökningar. Men det finns också risker med att i undersökning efter undersökning exponerar samma uppgifter om asocialitet i den offentliga diskussionen. 
Missbruk och psykisk sjukdom kommer, oavsett om undersökarna vill det eller ej, att tolkas som orsak till hemlöshet i våra föreställningar. Det har att göra med, som jag tidigare har påpekat, att allmänheten ofta förknippar grupper som »hemlösa» och »socialtjänstens klienter" med sociala problem orsakade av individuella brister. Undersökningsresultat som fokuserar på dessa brister kommer att ge ny näring åt sådana här uppfattningar, och kan t.o.m. minska allmänhetens intresse av att hjälpa de hemlösa. Det finns exempel i amerikanska surveyundersökningar på att de som förband hemlösheten med strukturella förhållanden var mer positiva till skattehöjningar och ökat bostadsbyggande än de som förband hemlösheten med individuella orsaker. De senare ville istället öka restriktionerna mot gruppen (Lee m.fl. 1990).

Enligt Baumohl är det viktigt att strukturella förhållanden också lyfts fram och att det blir någon slags balans mellan de båda grundläggande undersöknings- och forskningsperspektiven. Jan Halldin, Stig Åhs och Magnus Sundgren (1997) är inne på liknande tankar och hävdar att vi måste ha ett helhetsperspektiv, i högre utsträckning studera förändrade försörjnings- och bostadsförhållanden samt förändringar i vård- och omsorgsstrukturerna.

Det finns t.o.m. de forskare som frågar sig varför vi överhuvud taget förbinder hemlöshet med asocialitet och egna val. Timmer, Eitzen \& Talley (1994) resonerar på följande sätt. Om individuella förhållanden ligger bakom problemet, borde då inte proportionen hemlösa vara ungefär desamma i alla stora städer i världen? Personlig svaghet bör väl uppträda i samma proportioner på olika håll? $\mathrm{Om}$ personliga förhållanden skulle vara skäl till hemlöshet borde det finnas samma andel hemlösa i London, Paris och New York. Eftersom det inte förhåller sig så, bör då inte socioekonomiska förhållanden istället ligga bakom skillnaderna? Eftersom vi inte heller vet om det är hemlösheten som orsakar psykiska problem och missbruk eller tvärtom, bör vi vara försiktiga med att inrikta allt intresse på de hemlösas personliga brister, menar författarna.

Timmer, Eitzen \& Talley polemiserar mot den forskning som de anser alltför mycket inriktar sig på hemlösa människor, deras dryckesvanor, förekomsten av psykisk sjukdom osv och bortser från de strukturella förhållanden som genererar hemlöshet. Det finns naturligtvis också en risk med att hårddra den här typen av resonemang, dvs att forskarna går så långt att de helt bortser ifrån att individuella förhållanden har betydelse och bara lägger tonvikten vid strukturella förhållanden. Det är inte helt enkelt att jämföra olika huvudstäder som Timmer, Eitzen \& Talley gör. De strukturella förhållandena är olika. Det finns många led mellan strukturella förhållanden och enskilda individers hemlöshet som kräver en närmare analys. De kulturella förhållandena är olika i olika länder vilket kan påverka synen på de hemlösa, men också fattiga människors kulturella strategier. Det finns helt enkelt en risk för att forskarna hamnar i två ytterlighetspositioner dvs att antingen ensidigt knyta hemlösheten till individer eller strukturer.

De forskare som förespråkar att större hänsyn måste tas till strukturella förhållanden hävdar ofta att betingelserna för sådana analyser är mycket ogynnsamma, t.ex. ana- 
lyser av statistisk samvariation. De resonerar ungefär på följande sätt. Kvalitén på statistiska data om hemlöshet vad gäller omfattning, utbredning och varaktighet är så dålig att det är svårt att se hur de förhåller sig till andra data. Vi kan inte i dag, för att ta ett exempel, avgöra om antalet hemlösa stiger eller sjunker i takt med att arbetslösheten eller fattigdomstalen stiger eller sjunker. Peter Rossi pläderar därför i en artikel "Strategies for Homeless Research in the 1990's" - för behovet av longitudinella studier av hemlösheten (Rossi 1991, s. 1039 ff). Sådana longitudinella studier skulle öka möjligheterna att göra strukturella analyser. Men i dagens läge innebär bristen på data att forskning om hemlöshet som socialt problem missgynnas i förhållande till det perspektiv som lägger tonvikten på de hemlösa. Det går naturligtvis att hitta motargument till resonemangen ovan och visa på vikten av att inta ett inifrånperspektiv för att skapa förståelse för enskilda människors livshistorier.

Jag menar liksom Baumohl att det krävs en medvetenhet om perspektivvalet och dess konsekvenser och att motsättningarna mellan olika perspektiv lätt kan tvinga in forskarna i någon ytterlighetsposition.

\section{Exempel på ett etiskt dilemma: att fråga om asocialitet}

Det finns som jag antytt ovan många etiska dilemmor i hemlöshetsforskningen som gör sig gällande när det gäller såväl benämningar av de hemlösa, som valet av definitioner, valet av perspektiv, samt tolkning av resultat. För att illustrera denna ganska omfat- tande problematik skall jag diskutera ett dilemma, nämligen om det är riktigt att ställa frågor om de hemlösas missbruk och psykiska besvär och hur vi i så fall skall tolka de svar vi får.

Från myndigheternas perspektiv kan det självfallet vara av intresse att ställa den här typen av frågor. Kommunerna vill t.ex. veta hur många hemlösa som finns inom kommunen och hur problemen ser ut för att kunna besluta om hur vården skall dimensioneras. $V i$ vet att undersökarna kommer att hitta en viss procent som kommer att uppges ha psykiska problem eller missbruksproblem. ${ }^{8}$ Men vad säger egentligen sådana här siffror om vi inte relaterar dem till något?

Hur vi skall tolka resultaten beror på vad vi jämför med - normalbefolkningen eller andra grupper som befinner sig i samma situation, men som har lägenheter. Den amerikanske forskaren Sosin (1992) hävdar att de flesta forskare jämför hemlösa med vanliga medborgare och jämförelser med andra utsatta och sårbara grupper görs sällan. Det finns många i samhället som lever på gränsen till hemlöshet men bara en liten del av dessa blir hemlösa. Vore det inte rimligare att jämföra de hemlösa med dem som är på gränsen till hemlöshet, frågar han sig. Sosin har därför gjort en studie av hemlösa vid ett "Vulnerable Meal Program" (kan enligt svenska förhållanden närmast jämföras med en form av soppkök) i Chicago. Han har valt

8 Både i svenska och amerikanska undersökningar har man under senare tid funnit att mellan 1/5-del och en 1/4-del av de undersökta har psykiska problem eller missbruksproblem beroende på undersökninsmetodik m.m. Se t.ex. Socialstyrelsen 1994:15. 
denna grupp för att de som besöker programmet har en likartad problembild och utgör en väl avgränsad grupp som lever under mycket fattiga förhållanden, samtidigt som alla inte är hemlösa. Besökarna har svårt att hitta arbeten och har mycket låg inkomst. Sosin menar att omkring 72 procent av Chicagos hemlösa går på s.k. meal program. Han finner tre grupper i sin studie: de som inte tidigare varit hemlösa och försöker att undgå att bli det, de som tidigare varit hemlösa men fått bostäder och de som är hemlösa. Det finns inga dramatiska skillnader mellan de olika grupperna när det t.ex. gäller missbruk. Han polemiserar mot de som menar att alkoholism och psykisk sjukdom är den direkta orsaken till hemlöshet. Inte heller Timmer, Eitzen och Talley (1994) anser att det finns några hållbara belägg för att problem med alkohol skulle vara mer vanligt bland hemlösa än bland icke-hemlösa, men sårbara grupper. De hemlösa har egentligen större skäl att inte dricka än vad icke-hemlösa har. De hemlösa har mindre pengar, är mer övervakade, kommer inte in på härbärgen och kan bli överfallna om de är berusade. För att kunna pröva sådana här resonemang, som förmodligen vänder upp och ner på vanliga föreställningar, måste vi använda kontrollerade studier och kontrollgrupper, som väljs ut på ett rimligt sätt.

Vad kan vi då lära av Sosins resonemang? Vi måste vara försiktiga när vi tolkar uppgifter om missbruk, psykisk sjukdom, beteendeavvikelser och försöka relatera resultaten till jämförbara grupper innan vi drar allt för långtgående slutsatser. Jämförelser kräver olika typer av kontrollerade studier, men sådana görs sällan inom detta område.

En annan fråga är vilken kvalité insamla- de uppgifter om de hemlösas asocialitet egentligen har. Kan vi lita på uppgifterna och vilket ansvar har vi i så fall för att markera denna osäkerhet när resultaten presenteras? I undersökningarna ställs ofta frågor till myndighetsrepresentanter eller frivilligorganisationer om de hemlösas alkoholmissbruk och psykiska åkommor. Men företrädare för myndigheter och organisationer har sannolikt dåliga kunskaper om de utsattas verkliga alkoholkonsumtion och har svårt att bedöma psykisk sjukdom (de som svarar är sällan läkare). Amerikanska undersökningar visar t.ex. att det är lätt att dra slutsatser att alla som vistas i hemlöshetsmiljöer också dricker alkohol, eller att luggslitna personer är psykiskt särpräglade. Timmer, Eitzen och Talley (1994) visar att det inte alltid är så.

Tjänstemännen eller frivilligrepresentanterna träffar många gånger de hemlösa då de är i krislägen och pressade av omständigheterna och skall utifrån detta göra bedömningarna.

Det kan också finnas skäl för de som svarar på enkäterna att medvetet eller omedvetet nedvärdera eller överdriva problemen. En myndighetsrepresentant vill kanske skyla över problemen, eller lägga ansvaret på de hemlösa, för att slippa att få kritik för att kommunen inte arbetar tillräckligt förebyggande. En frivilligorganisation kan ha ett intresse av att legitimera en verksamhet ( $t$.ex. härbärge) och menar att gästerna är så dåliga att de inte kan bo i egna lägenheter. Hade de hävdat motsatsen hade de riskerat att rycka undan grunden för sin egen verksamhet. Genom att ställa frågor om alkohol- och narkotikamissbruk riskerar dessutom undersökarna att leda tankarna hos de som skall svara till att missbruk och psykisk 
sjukdom har något med hemlöshet att göra. Härtill kommer en rad andra metodologiska problem som jag skall redogöra för i nästa avsnitt.

Det finns alltså skäl att anta att uppgifter som lämnas om utsatta människors mycket personliga förhållanden omges av en stor osäkerhet. En viktig etisk fråga gäller hur vi skall ta ansvar för osäkra resultat om asocialitet. Det har att göra med att resultaten lätt kan misstolkas i den allmänna debatten och i slutändan riskerar att svartmåla de hemlösa eller förstärka myter och fördomar.

\section{Svårt att använda vanliga samhällsvetenskapliga metoder}

Det är problematiskt att använda vanliga samhällsvetenskapliga metoder i studier av hemlösa och andra utsatta människor. Det går t.ex. inte att skicka enkäter till människor som saknar en adress. Vidare är det svårt att genom registerstudier eller genom folk- och bostadsräkningen lokalisera dem. Hemlöshetsstudier där undersökarna har ambitionen att göra representativa undersökningar, brottas således med urvals-, generaliserbarhets- och mörkertalsproblem (Snow \& Anderson 1993, s. 30 ff). Det är också ett välkänt faktum att de hemlösa utgör bortfallet i de traditionella samhällsvetenskapliga undersökningar som använder sig av slumpmässiga urval och enkäter (Wagner 1993). Eftersom det i regel saknas kunskaper om hemlöshetspopulationernas storlek och inre struktur, är det även svårt att göra strategiska urval. Även om det teoretiskt skulle gå att göra sådana urval, skulle det förmodligen vara omöjligt att få kontakt med de hemlösa som valts ut eftersom det är sannolikt att en del i gruppen flyttar runt mellan olika övernattningsställen.

Eftersom det är svårt att få tag på de hemlösa är det lättare för forskare och undersökare att fråga myndigheter eller frivilligorganisationer och inhämta uppgifter indirekt. Men det är inte heller oproblematiskt att vända sig till de utsatta. David Wagner (1993, s. 7-8) hävdar att flera av de amerikanska hemlöshetsundersökningarna består av enstaka intervjuer med människor som befinner sig på härbärgen, hotell för akutboende, sjukvårdskliniker, soppkök och välgörenhetsinrättningarnas dagverksamheter. Eftersom det är svårt att hitta hemlösa på en lägenhetsadress är det därför naturligt att forskarna uppsöker dem på de ställen där de vistas. Enligt Wagner innebär det en risk för att asocialitetsproblemen överbetonas i resultaten eftersom det är de utslagna som frekventerar härbärgen och liknande ställen.

Generellt saknas det longitudinella studier om hemlöshet, men de få som finns indikerar att hemlösheten för de flesta berörda individer är av mer tillfällig karaktär. Enstaka intervjuer utförda i ett krisläge under en akut hemlöshetsperiod ger därför, enligt Wagner, andra resultat än forskarna skulle fått om de hade följt upp de hemlösa under en längre tid och intervjuat dem i olika faser av hemlösheten och vid hemlöshetsperiodens slut. Det är emellertid problematiskt att göra longitudinella studier av människor som saknar bostad.

Att fokusera på den synliga hemlösheten innebär vidare att vissa grupper, t.ex. kvinnor eller de som inte besöker myndigheter och härbärgen blir underrepresenterade 
(Snow \& Anderson 1993). I den hemlöshetsdefinition som vi använt i Sverige under 1990-talet räknas också andra grupper än de mest synliga och uppenbara in bland de hemlösa. I Socialstyrelsens definition som använts i rikstäckande räkningar både 1993 och 1999 och i ett antal andra undersökningar heter det bl.a. att: „Till de hemlösa räknas också personer som tillfälligt bor hos kompisar eller bekantaw. ${ }^{9}$ Det innebär att hela gruppen arbetslösa ungdomar, som flyttar hemifrån och tillfälligt bor hos kompisar, i avvaktan på de skall etableras på bostadsoch arbetsmarknaden, räknas som hemlösa. Det är dock sällan eller aldrig vi ser några utsagor från denna grupp. Inte heller ser vi dessa ungdomar figurera i massmedier eller frivilligorganisationernas annonser vid jultid. Det är trashankarna som exponeras.

Jag menar att sådana här grundläggande metodologiska svårigheter (dvs. att det är svårt att göra urval, att det svårt att få tag på vissa grupper hemlösa och få deras perspektiv, att studier ofta görs då de hemlösa befinner sig i kris, att uppföljningar saknas och att myndigheter ofta får definiera problemen) sällan diskuteras i undersökningar eller kartläggningar av de hemlösa eller relateras till resultaten.

\section{Exempel på tolkningsproblem: att förstå hemlösas utsagor}

Enligt välfärdsstatens logik skall inte människor kunna bli hemlösa. Rätten till bostad är djupt förankrad i de utvecklade industristaterna. Vi förutsätter att människor som

9 Socialstyrelsen 1994:15 s. 115. mot förmodan hamnar på gatan skall få hjälp av samhälle eller sociala nätverk. Det är lätt att se de hemlösa som frihetsälskande original. Den här logiken är så stark hos oss som lever ett socialt tryggt liv att det finns risk för att vi, medvetet eller omedvetet, misstror de hemlösas berättelser om hur de hamnat på gatan eller pekar på motsägelser, luckor eller inkonsekvenser i deras resonemang och bygger upp undersökningar med dessa förutsättningar. Utifrån de hemlösas logik är det inte alls säkert att resonemangen är så motsägelsefulla (Timmer, Eitzen \& Talley 1994, Wagner 1993).

Huvudfrågan i det här resonemanget gäller hur vi skall tolka utsatta människors utsagor. Det finns mycket att säga om detta problem. En fråga gäller hur de hemlösa själva påverkas av de myter och föreställningar som omger dem och hur detta återspeglar sig i intervjusvaren.

Björn Halleröd (1993) har i en undersökning från början av 1990-talet visat att en stor del av befolkningen tror att många socialbidragstagare är utslagna. Det finns inga liknande undersökningar om de hemlösa, men utifrån andra klientundersökningar är det rimligt att anta att samma sak gäller dem. Jönsson och Starrin (1998) har i en undersökning visat att arbetslösa som söker socialbidrag tror att allmänheten anser att de är lata och utnyttjar systemet och har alkohol- eller drogproblem. Det innebär att grupper som socialbidragstagare och hemlösa är utsatta för samma myter och hörsägner som allmänheten och själva blir kritiska i sin värdering av sina olycksbröder (Golding \& Middleton 1982, Rank 1994). Det finns en risk för att klienter och andra utsatta grupper tar till sig och införlivar sådana 
här nedvärderande attityder, myter och hörsägner och tillämpar dem i beskrivningen av sig själva (jfr. Abo El Nasr 1989, Salonen 1998).

Till detta skall läggas att klienter som är vana att umgås med myndigheter, ständigt inför myndigheterna måste återge sitt liv på ett sätt som passar myndigheterna. Många hemlösa har berättat om sina liv för åtskilliga poliser, socialarbetare, representanter för frivilligorganisationer och vårdpersonal. De får också läsa utredningar, t.ex. vid intagning på vårdanstalt för missbrukare, som myndigheterna har gjort där deras liv sammanfattas. Etnologen Birgitta Svensson (1997) har visat att myndigheternas biografering kan innebära att biografierna skapar sina objekt.

Liksom andra klienter känner de hemlösa skam över att inte kunna klara sig själva. De upplever att de behöver «tigga myndigheterna om hjälp» eller känner sig som andra klassens medborgare (Julkunen 1992). Rank (1994) har visat att utsatta människor utvecklar olika strategier för att handskas med omgivningens negativa attityder. Den norska forskaren Solheim (1995) visar t.o.m. att många klienter får utkämpa en hård kamp för att upprätthålla självrespekten.

I intervjuer med hemlösa är det t.ex. ganska vanligt att de hemlösa lägger skulden på sig själva. De här erfarenheterna har hemlöshetsforskare både från Sverige och USA. Uttalanden av följande slag förekommer således: "sådana som jag kan inte bo i lägenheter", ,jag har mig själv att skyllaw. I "Söndags-

10 SvD 25/1 1998. „Jag har blivit för gammal för utesvängen« av Karin Thunberg. Jag bygger min framställning på detta reportage. intervjun" i Svenska Dagbladet 1998 porträtterades en 70-årig man som varit hemlös nästan hela sitt liv. ${ }^{10}$ Han konstaterade följande: „Och jag ångrar ingenting. Fick jag leva om mitt liv skulle det se ungefär likadant ut, /.../ det var inga hemska år, inget elände. Snarare har jag haft ett glatt liv med många ljusa minnen. Av frihet. Och kamratskap.« De svåra minnena, dem säger den intervjuade att han supit bort.

Men hur skall vi tolka sådana här uttalanden? Är det verkligen så att människor väljer sin hemlöshet? Även om de säger att de valt, är det då frågan om verkliga val? Går det att överleva som hemlös någon längre tid om man är bitter och känner sig som ett offer? Går man inte i så fall under? Måste inte alla ge sitt liv en rationalitet och mening?

Det är inte lätt att tolka intervjuer med utsatta människor, särskilt om vi gör intervjuerna under en akut hemlöshetsperiod. Det är frågan om mycket komplexa förhållanden. Vi skall absolut inte misstro de hemlösas utsagor. Det är deras verklighet. Men David Wagner menar att det krävs att vi går djupt in i de hemlösas värld, gör omfattande intervjuer och följer de hemlösa under långa tid för att rätt förstå dem och rätt tolka deras liv och utsagor. Men det är inte många forskare som arbetar så $i$ dag.

\section{Avslutande reflektioner}

Min uppfattning är att det är svårt att forska om hemlösa och andra utsatta människor. Många av de vanliga samhällsvetenskapliga teknikerna är inte tillämpbara. Det är t.ex. svårt att avgöra hur många hemlösa som egentligen finns. Denna osäkerhet gör att det är omöjligt att se hur och om hemlöshe- 
ten samvarierar med arbetslöshet, antalet vräkningar osv. Eftersom vi inte vet hur totalpopulationen ser ut är det också besvärligt att göra olika typer av urval. Även om vi skulle lyckas att göra urval är det av förklarliga skäl svårt att få tag på människor som saknar en adress och som inte bor på härbärgen och liknande övernattningsställen. Vidare är det svårt att göra uppföljningar av människor som saknar adress. Antingen får undersökarna förlita sig på enstaka intervjuer eller att fråga myndigheter och frivilligorganisationer. I vissa avseenden kan det emellertid vara en tveksam metod eftersom det bara ger ett perspektiv på problemen. Ofta vet vi alltså inte hur säkra, representativa eller heltäckande resultaten är.

I forskningen om sociala problem brukar man skilja mellan olika nivåer. Först talas om en överordnad nivå där strukturella förhållanden anses skapa grogrund för olika problem. Den andra nivån är organisatorisk och undersöker myndigheters och organisationers förhållanden till olika problem och den tredje nivå handlar om medborgarna dvs. bärarna av problemen. Svårigheterna att studera på vilket sätt hemlöshet är en konsekvens av strukturella och organisatoriska förhållanden gör att många studier är inriktade på enskilda individer. Det finns ingen anledning att kritisera detta. Men det behövs också andra typer av studier t.ex. jämförelser av olika kommuner med liknande struktur men med många respektive få hemlösa.

Osäkra resultat och undersökningsresultat som ofta fokuserar på individuella i stället för på samhälleliga eller organisatoriska förhållanden kan lätt ge näring åt vissa positioner i en infekterad samhällsdebatt - t.ex. att fattigdom, hemlöshet och utsatthet har individuella orsaker och beror på personliga brister. Det är också ett problem om myndighetsbeslut grundas på undersökningsresultat som i grunden är ganska osäkra. J Jag menar att det krävs insatser av grundforskningskaraktär för att kritiskt granska och utveckla olika metoder i forskningen om utsatta människor, där vi t.ex. kan jämföra vad olika perspektiv och metoder ger för resultat.

\section{Summary \\ Doing research on vulnerable people}

The article discusses problems of methodology and research ethics in the study of homeless people and other vulnerable groups. Even the act of finding concepts or words for vulnerable groups creates problems, since they are often coloured by ideological notions. It is easy to build in ideas into the preliminary assumptions of a study. There are two main rival perspectives on homeless- ness, which often lead to different methodological implications. One perspective is based on the asociality of the homeless and puts the emphasis on how the homeless should be cared for and treated. The other perspective analyses homelessness as a social problem and studies deficiencies in housing and welfare policy. Today there is a poor balance between these perspectives, and 
most studies proceed from the individual perspective. It is problematic to use ordinary social science methods in studies of vulnerable people. Studies in which the researchers have the ambition to conduct representative investigations have to grapple with problems of selection, generalizability, and dark figures. Isolated interviews conducted in crisis situations, for example, during a period of acute homelessness, give results that differ from what the researchers would have obtained if they had followed up the homeless over a long period and interviewed them at different phases of homelessness and at the end of the homeless period. Certain groups, such as women or people who do not visit authorities or shelters, are under-represented. In my opinion, research efforts are needed, with the character of basic research, to develop various methods for doing research on vulnerable people.

\section{Litteratur}

Abo El Nasr, M (1989) "The term 'client ‘ in the social work profession." International Social Work, 32, 311-318.

Baumohl, Jim (ed.) (1996) Homelessness in America, Arizona: The Oryx Press.

Christophs, Irja (1997) Utan hem - Långt hemifrån. En rapport om hemlösa kvinnor och män, med utomnordiskt ursprung, på Stockholms kommuns härbärgen, FoU-rapport 1997:5, Resursförvaltningen för Skola och Socialtjänst, Stockholm.

Culhane P. Dennis \& Randall Kuhn (1998) „Patterns and Determinants of Public Shelter Utilization among Homeless Adults in New York City and Philadelphia", Journal of Policy Analysis and Managment(17) 1:23-43.

Espeland, Vigdis (1981) „Blommor från rännstenen- en studie av muntlig tradition och livsvillkor bland hemlösa alkoholister i Bergen" Tradition och miljö. Ett kulturekologiskt perspektiv (red. Lauri Honko \& Orvar Löfgren), Lund: Liber.

Foucault, Michel (1986) Vansinnets historia under den klassiska epoken. Lund: Arkiv.

Foucault, Michel (1987) Övervakning och straff: fängelsets födelse. Lund: Arkiv.

Golding, Peter \& Susan Middleton (1982) Images of Welfare. Press and Public Attitudes to Poverty. Oxford: Robertson.

Grosin, Lennart \& Johan Norman (1974) Att leva på samhällets botten. Rapport om de yngre hemlösa männens livssituation, Lund: Studentlitteratur.

Hagelin, Lars Anders (1977) „Fyllegubbar på två ungkarlshotell", Fataburen: 75-87.

Halldin, Jan, Stig Åhs och Magnus Sundgren (1997) "Hemlösheten i Stockholm med fler kvinnor och psykiskt sjuka - en social och socialmedicinsk utmaning", Socialmedicinsk tidskrift 10: 452-460.

Halleröd, Björn (1993) "Åsikter om socialbidragstagare« i Halleröd, B, Marklund, S, Nordlund A \& Stattin M, (red) Konsensuell fattigdom-En studie av konsumtion och attityder till komsumtion. Umeå Studies in Socilogy 104.

Hessle, Sven (1977) Att forska om utsatta. En etikdiskussion utifrån intervjuer med intervjuare. Rapport nr 32 Barnbyn Skå, Metodbyrå 1, Stockholms Socialförvaltning.

Himmelfarb, Gertrude (1984) The idea of poverty, London: Faber.

Inghe Gunnar \& Maj-Britt Inghe (1970) (original 1967) Den ofärdiga välfärden, Stockholm: Tidens förlag/Folksam.

Isaksson, Kerstin, Johan Norman \& Lars Svedberg (1978) Överlevnadsstrategier bland hemlösa och socialt utslagna, Stockholm: Tidens Förlag.

Julkunen, Ilse (1992) "Ta missnöjet på allvar!» Nordiskt Socialt arbete 2, 45-55.

Järvinen, Margaretha (1998) Det dårlige selskap. 
Misbruk, behandling, omsorg. Holte: SOCPOL.

Jönsson, Leif Roland, Bengt Starrin (1998) „Ett annat liv. En studie av arbetslöshetens konsekvenser bland arbetslösa i Skåne». Meddelanden från Socialhögskolan i Lund 1998:5.

Lee, Barett A. Jones, Sue Heinze, Lewis, David W. (1990) „Public Beliefs About the Causes of Homelessness" Social Forces (69) 1 (sept 1990): 253-265).

Petersson Birgit (1983) Den farliga underklassen. Studier i fattigdom och brottslighet i 1800-talets Sverige, Umeå universitet. Stockholm: Almqvist \& Wiksell International.

Ralston, Meredith L. (1996) „Nobody Wants to Hear Our Truth": Homeless Women and Theories of the Welfare State, Westport, Conn:

Greenwood Press.

Ramsø Odd, Frank Burmann, Per-Ole Johansen, \& Torbjørn Kalberg (1971) På livet... Fra filleproletariatet $i$ Oslo, Oslo: Universitetsforlaget.

Rank, Mark R. (1994) » A View from the Inside Out: Recipients'Perception of Welfare». Journal of Sociology and Social Welfare (21) 2, 2747.

Eliasson, Rosmari (1995) Forskningsetik och perspektivval. Lund: Studentlitteratur.

Rossi, Peter H. (1991) "Strategies for Homeless Research in the 1990's", Housing Policy Debate (2) 3:1029-1055.

Sahlin, Ingrid (1992) "Att definiera hemlöshet", Sociologisk Forskning 2:51-71.

Salonen, Tapio (1998) „Klient« i Denvall, V \& Jacobson, T (red) Vardagsbegrepp i socialt arbete - Ideologi, teori och praktik. Stockholm: Nordstedts juridik.

Snow, David A. \& Leon Anderson (1993) Down on Their Luck, A Study of Homeless Street People,
Berkeley/Los Angeles/Oxford: University of California Press.

Socialstyrelsen (1994) De bostadslösas situation $i$ Sverige, Rapport 1994:15, Stockholm.

Solheim, L, J (1995) Socialhjelp og sjovrespekt, Ostlandsforskning. Rapport nr 20.

Sosin, Michael R. (1992) „Homeless and Vulnerable Meal Program Users: A Comparison Study", Social Problems (39) 2:170-185.

Sosin, Michael R., Irving Piliavin \& Herb Westerfelt (1990) »Toward a Longitudinal Analysis of Homelessness", Journal of Social Issues (46) 4:157-174.

SvD25/1 1998.

Svensson , Birgitta (1997) The Power of Biography: Criminal Policy. Person, Life and the Formation of Identites in the Swedish Welfare State, $\mathrm{i}$ Reed-Danahay, Deborah E(ed). Autoethnography-Rewriting the Self and the Social, Oxford/New York, Berg.

Swärd, Hans (1998) Hemlöshet. Fattigdomsbevis eller välfärdsdilemma. Lund: Studentlitteratur.

Timmer, Doug A., D. Stanley Eitzen \& Kathryn D. Talley (1994) Paths to Homelessness. Extreme Poverty and the Urban Housing Crisis, Boulder/San Francisco/Oxford: Westview Press.

Wagner, David (1993) Checkerboard Square. Culture and Resistance in a Homeless Community, Boulder/San Francisco/Oxford: Westview Press.

Wiktorin Marianne (1980) Bostad åt alla? Om svaga grupper påbostadsmarknaden, Statens institut för byggnadsforskning, Stockholm: Liber förlag.

Ågren, Gunnar, Edda Berglund, Erik Finne \& Paul Franér (1997) Hemlösa i Stockholm 1996, Stockholm: FoU-rapport 1997:9. 